\title{
Self-Similar Solutions in the Theory of Underwater Landslide Dynamics in Inclined Canyons
}

\author{
Narcisse Zahibo*,1, Efim Pelinovsky $^{1,2}$, Tatiana Talipova ${ }^{1,2}$ and Irina Nikolkina ${ }^{1,3}$ \\ ${ }^{I}$ Physics Department, University of Antilles and Guyane, Pointe-à-Pitre, Guadeloupe, F.W.I., France \\ ${ }^{2}$ Department of Nonlinear Geophysical Processes, Institute of Applied Physics, Nizhny Novgorod, Russia \\ ${ }^{3}$ Department of Applied Mathematics, Nizhny Novgorod State Technical University, Nizhny Novgorod, Russia
}

\begin{abstract}
The landslide motion in inclined underwater canyons is described in the framework of basic equations of the gravity driven shallow-water flows. A Coulomb (sliding) friction term is included in the model. The analytical self-similar solutions are obtained in the explicit form. The spatial structure of avalanche that depends on the cross-section of the inclined channel is studied. Temporal variation of landslide parameters for different cross-sections of the channel is analyzed. Obtained results can be used to test 2D numerical models of landslide motion and tsunami generation by underwater landslides.
\end{abstract}

Keywords: Landslide, Underwater

\section{INTRODUCTION}

The submarine and aerial landslides are frequently reported as the sources of tsunami waves. In fact, such situation is typical for Lesser Antilles in Caribbean. The pyroclastic flows were generated several times on the Montserrat Island due to continued volcano activity and caused three tsunami events recorded in Guadeloupe and Montserrat in the last decade [1-3] the repetition of such events is rather high. Various data of tsunami generation and propagation can be found in books [4-6] Diverse analytical and numerical models are developed to describe tsunamis generated by landslides. In series of papers [1,7-14] the landslide is assumed as a solid block moving under the joint action of gravity and friction. As its motion is known the hydrodynamic equations for tsunami waves are solved with determined external source. More realistic models of tsunami generation include "two-layer" approach which jointly describes tsunami wave and a landslide propagation influencing one another. Such models of underwater landslides are based on homogeneous shallow-water flows that are deformed during propagation [15-22]. These models use various approximations of vertical structure of velocity field (uniform as in ideal fluid, or parabolic for viscous fluid), as well as different approximations of the friction law (Coulomb friction, Chezyquadratic friction and so on); the derivation of the mentioned models can be found for instance [23].

The number of analytical solutions of gravity driven shallow-water flow is limited. self-similar solutions called parabolic cap and M-wave similarity solutions with application to the avalanche dynamics were constructed in $[24,25]$. Such solutions are obtained for a chute of constant inclination

*Address correspondence to this author at the Physics Department, University of Antilles and Guyane, Pointe-à-Pitre, Guadeloupe, F.W.I., France; Tel: (+59) 05904831 07; Fax: (+59) 05904831 05;

E-mail: harcisse.zahibo@uniy-ag.fr and constant bed friction angle. [16] found the analytical solution of a one-dimensional dam-break problem over inclined plane taking into account Coulomb friction. It was actively used to test the numerical models applied to evaluate the hazard of the volcano eruption in the Lesser Antilles and tsunami waves induced by landslides [21].

However, real underwater landslides move in basins of more complicated bottom geometry. As a rule, they move in submarine canyons which are generally diverging, converging or twisted. Anyway some of them have straight parabolic-like shapes (Fig. 1). We provide here new analytical solutions for underwater landslides in inclined channels of constant slope with the specific parabolic-like cross-section taking into account Coulomb friction. New effects in the landslide dynamics comparably to those known for the 1D motion along an inclined plate are related with the paraboliclike cross-section shape of the canyon.

The paper is organized as follows. The basic model to describe the landslide motion that represents gravity driven shallow-water flow in a narrow inclined channel of parabolic-like cross-section is briefly given in section 2 . For narrow channels the basic equations are also 1D but they contain additional coefficients that determine the parabolic-like cross-section. The self-similar solution for the landslide of finite length and symmetrical shape in the inclined canyons is found in the section 3. The discussion of obtained results is given in the conclusion.

\section{GOVERNING EQUATIONS OF GRAVITY DRIVEN SHALLOW-WATER FLOW}

The shallow-water system is the basic system to describe gravity driven flow (submarine landslide), various analytical and numerical models realized the shallow-water equations can be found in $[23,26]$. Here we will assume that the landslide can be presented by the flow of incompressible fluid 


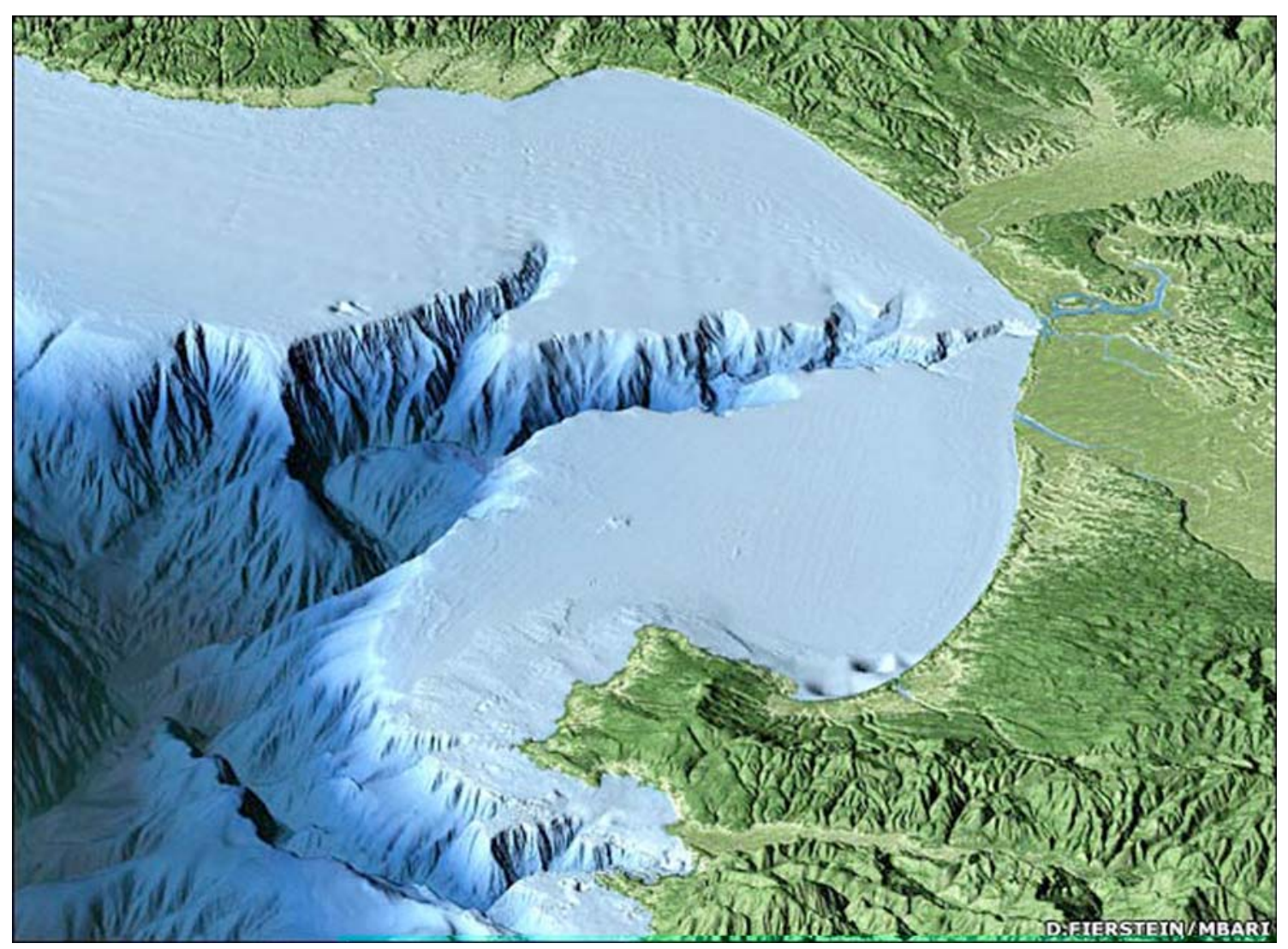

Fig. (1). View of Monterey, Soquel and Carmel Canyons (Monterey Bay Aquarium Research Institute data [28]).

with the Coulomb-type friction term. In the first approximation we will assume that the dynamics of the underwater landslide can be described independently from tsunami waves induced by landslides see [7,8]. Formally, it is possible if the landslide density exceeds significantly the water density. In the system of coordinates linked to the topography the equations of mass and momentum conservation have the following form

$$
\begin{aligned}
& \frac{\partial S}{\partial t}+\frac{\partial}{\partial x}(S u)=0, \\
& \frac{\partial u}{\partial t}+u \frac{\partial u}{\partial x}+g \cos \theta \frac{\partial h}{\partial x}=g \sin \theta-\mu g \cos \theta
\end{aligned}
$$

where $S(x, t)$ is the area of the cross-section of the channel, $h(x, t)$ is the height along $x$-axis of channel, and $u(x, t)$ is the mean velocity flow, $g$ is the acceleration due to gravity, $\theta$ is the slope angle along $x$-axes, $\mu=\tan (\varphi)$ is the sliding friction coefficient, and $\varphi$ is the dynamic friction angle. The value of $\varphi$ depends on the landslide material, and is small for sand and large for granular debris avalanche. One-dimensional equations are valid if the inclined channel (submarine canyon) is narrow, and water flow is uniform in the transversal direction. This 1D system can be derived from twodimensional equations of gravity-driven flow given for instance in books $[26,27]$.

To close this system, the function $S(h)$ should be determined. If the cross-section has a parabolic-like shape (see Fig. 2),

$$
z(y)=k|y|^{m}
$$

with positive arbitrary constants, $k$ and $m$, the function, $S$ is calculated explicitly

$$
S=\frac{2 m}{(m+1) k^{1 / m}} h^{(m+1) / m}
$$

In general cross-section of the channel is parabolic, triangular or concave for different values of $m$, (see Fig. (2)).

As a result, the equation (1) transforms to

$$
\frac{\partial h}{\partial t}+u \frac{\partial h}{\partial x}+\frac{m}{m+1} h \frac{\partial u}{\partial x}=0
$$

and the system of equations (2) and (5) becomes closed. It differs from the "classical" one-dimensional shallow-water equations $[16,26]$ in the constant coefficient $m /(m+1)$, and may be transformed to them as $m \rightarrow \infty(S \sim h)$.

Below we assume the constant slope of the inclined channel $\theta$, which should be relatively high $(\theta>\varphi)$ to provide the landslide motion.

The basic system of gravity driven flow, (2) and (5), is analyzed below. Mathematically, it is a hyperbolic system with constant coefficients. As for water waves above inclined bottom [27, 29-31], the Riemann invariants can be found explicitly

$$
I_{ \pm}=u \pm 2 \sqrt{\frac{m+1}{m} g h \cos \theta}-g \alpha t,
$$




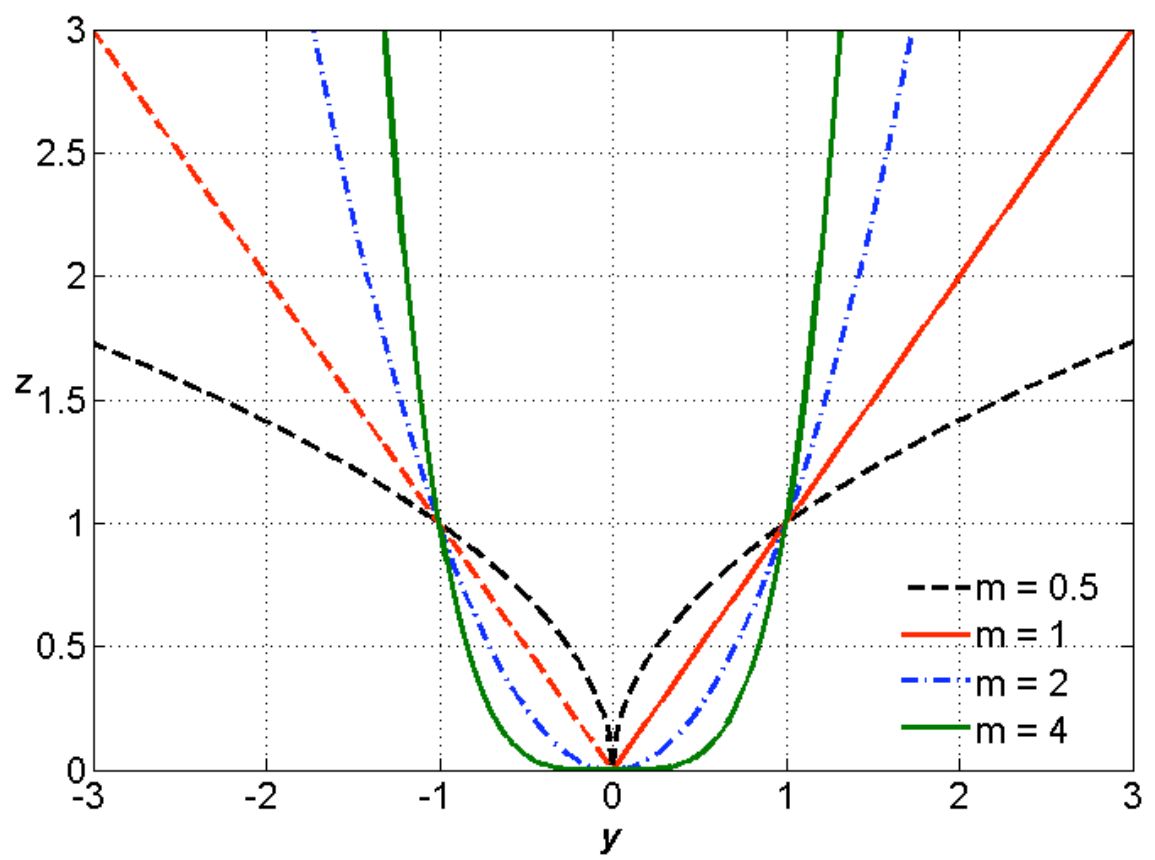

Fig. (2). Cross-section of the channel computed for $\mathrm{k}=1$.

where

$$
\alpha=\sin \theta-\mu \cos \theta>0,
$$

and the system (5) - (2) can be re-written in the form

$$
\frac{\partial I_{ \pm}}{\partial t}+c_{ \pm} \frac{\partial I_{ \pm}}{\partial x}=0
$$

where characteristic speeds are

$$
c_{ \pm}=\frac{3 m+2}{4(m+1)} I_{ \pm}+\frac{m+2}{4(m+1)} I_{\mp}+g \alpha t .
$$

It should be mentioned that the equations (8) - (9) appear in the problems of long water wave runup on the coast including tsunami wave runup [27, 29-31] but the main difference here is that the bottom slope is not small (as in "runup problems") and the Coulomb-type friction is not neglected. The "landslide solutions" can not be directly obtained from the "tsunami solutions" because mathematically, the initial and boundary conditions for tsunami waves and landslide dynamics differ. Physical variables, $h(x, t)$ and $u(x, t)$ are found from the algebraic equations (6) and the down slope component of the velocity field $(g \alpha t)$ propagated under the action of gravity can be eliminated by use of

$$
\begin{gathered}
u(x, t)=g \alpha t+v(x, t), \\
v(x, t)=\frac{I_{+}+I_{-}}{2}, \\
h=\frac{m}{16 g \cos \theta(m+1)}\left(I_{+}-I_{-}\right)^{2} .
\end{gathered}
$$

where $\alpha(>0)$ depends on the slope angle and friction coefficient, see (7). Another useful development is the change of coordinates, the accelerated reference system can be written as

$$
X=x-\frac{g \alpha t^{2}}{2}, \quad t=t .
$$

In this case the basic equations (2) and (5) transform to

$$
\begin{aligned}
& \frac{\partial h}{\partial t}+v \frac{\partial h}{\partial X}+\frac{m}{m+1} h \frac{\partial v}{\partial X}=0 \\
& \frac{\partial v}{\partial t}+v \frac{\partial v}{\partial X}+g \cos \theta \frac{\partial h}{\partial X}=0
\end{aligned}
$$

The system (14) - (15) will be used below to study the unsteady dynamics of the landslide in the inclined canyon.

\section{SELF-SIMILAR SOLUTION}

Let us try to find self-similar solutions of the equations (14) and (15). They can be obtained using the self-similar transformation of coordinates

$$
\eta=\frac{X}{L(t)}, \quad t=t
$$

which transforms equations (14) and (15) to

$$
\begin{aligned}
& \frac{\partial}{\partial t}\left(h^{\frac{m+1}{m}}\right)+\frac{v-\eta d L / d t}{L} \frac{\partial}{\partial \eta}\left(h^{\frac{m+1}{m}}\right)+\frac{h^{\frac{m+1}{m}}}{L} \frac{\partial v}{\partial \eta}=0, \\
& \frac{\partial v}{\partial t}+\frac{v-\eta d L / d t}{L} \frac{\partial v}{\partial \eta}+\frac{g \cos \theta}{L} \frac{\partial h}{\partial \eta}=0 .
\end{aligned}
$$

Similar system of the equations (at $m \rightarrow \infty$ ) with application to the avalanche dynamics is studied in the [26]. Second term in both equations can be eliminated if we determine velocity distribution in the landslide body as

$$
v=\eta \frac{d L}{d t}=\frac{X}{L} \frac{d L}{d t} .
$$




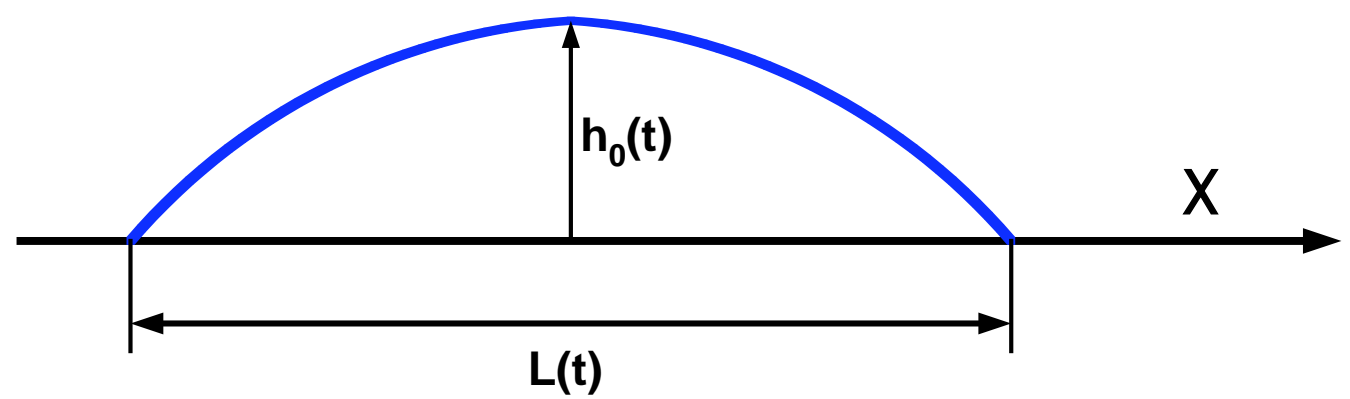

Fig. (3). Parabolic cap shape of the avalanche in longitudinal direction.

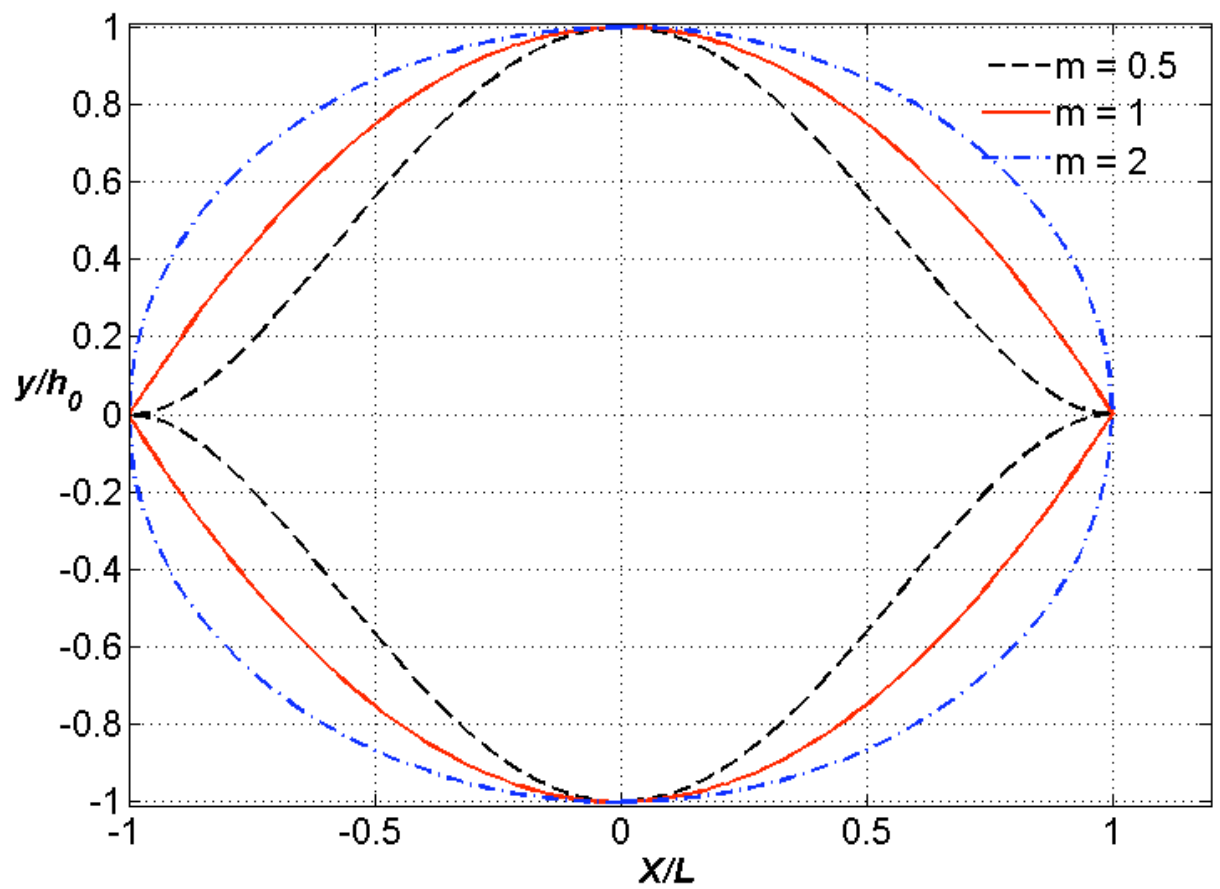

Fig. (4). Landslide contours in the accelerated reference system in different channels.

After substitution of (19) in (17) and (18) we obtain two differential equations for landslide height with respect to variables $t$ and $\eta$

$$
\begin{aligned}
& \frac{\partial}{\partial t}\left(h^{\frac{m+1}{m}}\right)+\frac{d L / d t}{L} h^{\frac{m+1}{m}}=0, \\
& \frac{\partial h}{\partial \eta}+\frac{\eta L d^{2} L / d t^{2}}{g \cos \theta}=0 .
\end{aligned}
$$

Both equations are integrated and the adequate choice of constants can be written as

$$
h=h_{0}(t)\left(1-\eta^{2}\right), \quad h_{0}(t)=\frac{L d^{2} L / d t^{2}}{2 g \cos \theta},
$$

where the landslide length $L(t)$ is a solution of

$$
L^{\frac{2 m+1}{m+1}} \frac{d^{2} L}{d t^{2}}=q
$$

and $q$ is determined by the initial spreading of the landslide. So, the underwater landslide has a parabolic cap shape in the longitudinal direction for any $m$ (Fig. 3), but its height and length depend on the cross-section of the inclined channel. For an inclined plate, the parabolic cap solution was obtained in [24] and its time evolution is quantitatively investigated. This solution is reproduced in the book [24].

The spatial structure of avalanche computed using the equation (3) depends on the cross-section of the channel (Fig. 4). The avalanche edge is quasi beak-shaped in the channel of the cross section $(m=0.5)$ and near lozengeshaped in the triangular cross section $(m=1)$; further increasing of the incurvature of channel leads to formation of ellipsoidal-shaped gravity flows $(m>1)$.

In general, equation (23) is integrated once

$$
\left(\frac{d L}{d t}\right)^{2}=p^{2}\left[1-\left(\frac{L_{0}}{L}\right)^{\frac{m}{m+1}}\right]
$$

where

$$
p=\sqrt{\frac{2 q(m+1)}{m L_{0}^{m / m+1}}} .
$$




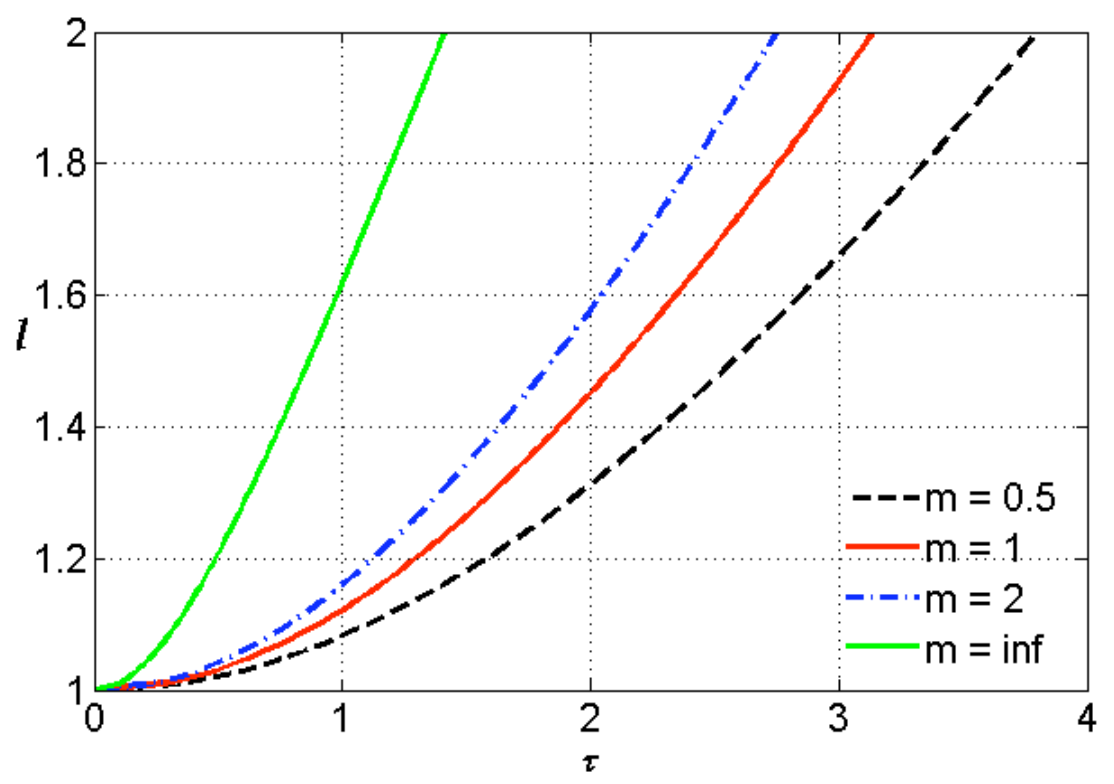

Fig. (5). Time evolution of the length of the parabolic cap landslide in different channels.

here we used the initial condition $L(t=0)=L_{0}$. In the variables

$$
l=\frac{L}{L_{0}}, \quad \tau=t p^{2} L_{0}^{2}
$$

The equations (24) are solved by quadratures

$$
\tau=\int_{1}^{l} \frac{d x}{\sqrt{1-x^{-\frac{m}{m+1}}}}
$$

For some values of $m$ (specific cross-section of shape of the canyon) the integral (27) can be evaluated:

$$
\begin{aligned}
& \tau=\sqrt{1-\frac{1}{l^{1 / 3}}}\left(l+\frac{5}{4} l^{2 / 3}+\frac{15}{8} l^{1 / 3}\right)+\frac{15}{16} \log \left[2 l^{1 / 3}\left(\sqrt{1-\frac{1}{l^{1 / 3}}}+1\right)-1\right], \\
& (m=0.5), \\
& \tau=\sqrt{1-\frac{1}{l^{1 / 2}}}\left(l+\frac{3}{2} l^{1 / 2}\right)+\frac{3}{4} \log \left[2\left(\sqrt{1-\frac{1}{l^{1 / 2}}}+1\right) \sqrt{l}-1\right], \\
& \tau=\sqrt{1-\frac{1}{l^{2 / 3}}}\left(l+2 l^{1 / 3}\right),(m=2), \\
& \tau=\sqrt{1-\frac{1}{l^{3 / 4}}} \cdot l+5(-1)^{7 / 6} \cdot \sqrt{1+(-1)^{1 / 3}} \cdot\left[(3+i \sqrt{3}) E\left(\eta_{1} \mid k_{1}\right)+\right. \\
& \left.(-1-i \sqrt{3})\left(\eta_{1} \mid k_{1}\right)\right] \Gamma, \quad(m=3), \\
& \tau=l \sqrt{1-\frac{1}{l^{4 / 5}}}-\frac{3 \cdot l^{2 / 5}}{\sqrt{1-l^{4 / 5}}} \sqrt{1-\frac{1}{l^{4 / 5}}}\left(E\left(\eta_{2} \mid k_{2}\right)-F\left(\eta_{2} \mid k_{2}\right)\right) \\
& (m=4), \\
& \tau=\sqrt{l(l-1)},(m=\infty),
\end{aligned}
$$

where

$$
\Gamma=\frac{\left(l^{3 / 4}-1\right)^{8 / 2} l^{-1 / 4} \sqrt{\left((-1)^{1 / 3} l^{1 / 4}+1\right)\left((-1)^{2 / 3} l^{1 / 4}-1\right)}}{2\left(2\left(-1+(-1)^{2 / 3}\right)+l^{3 / 4}+\sqrt{l}+l^{1 / 4}\right) \sqrt{l^{1 / 4}-1}},
$$

and $F(x, k)$ and $E(x, k)$ are the elliptic integrals of first and second order correspondingly

$$
F(\eta, k)=\int_{0}^{\eta} \frac{d \eta}{\sqrt{1-\eta^{2}} \sqrt{1-k^{2} \eta^{2}}}, \quad E(\eta, k)=\int_{0}^{\eta} \frac{\sqrt{1-k^{2} \eta^{2}} d \eta}{\sqrt{1-\eta^{2}}}
$$

and

$$
\eta_{1}=l^{1 / 5}, \quad k_{1}=-1, \quad \eta_{2}=\sqrt{\frac{2 l^{1 / 4}(3+i \sqrt{3})}{l^{1 / 4}-1}}, \quad k_{2}=\frac{-i+\sqrt{3}}{i+\sqrt{3}} .
$$

Solution (28) for $m=\infty$ (inclined plate) is also given in Pudasaini and Hutter (2007).

The length of the parabolic cap varies in time depending on the cross-section of shape; see Fig. (5) (in dimensionless variables), it increases faster for concave channels (at the same values of spreading coefficient $p L_{0}$ ).

For large times the landslide length varies almost linearly in time

$$
l(\tau) \approx \tau-\frac{1+m}{2} \tau^{\frac{1}{1+m}}
$$

Using (22) and (28) the maximal landslide height can be calculated, Fig. (6).

On the large times the landslide height is described by power asymptotic

$$
h(t) \sim L^{-\frac{m}{m+1}} \sim t^{-\frac{m}{m+1}} .
$$

For narrow channels the landslide height decreases slowly, in particular for channels of parabolic cross section, $L \sim t^{-2 / 3}$ 


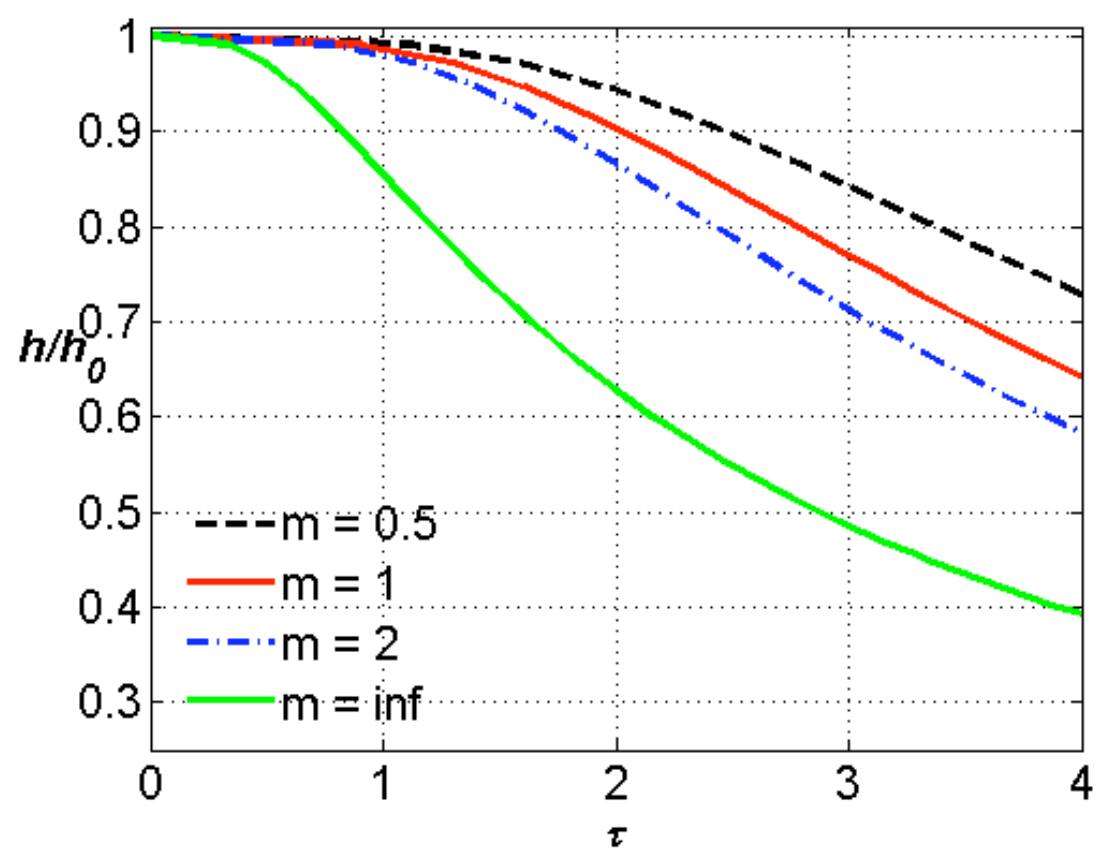

Fig. (6). Time evolution of height of parabolic cap landslide in different channels $\left(L_{0}=1\right)$.

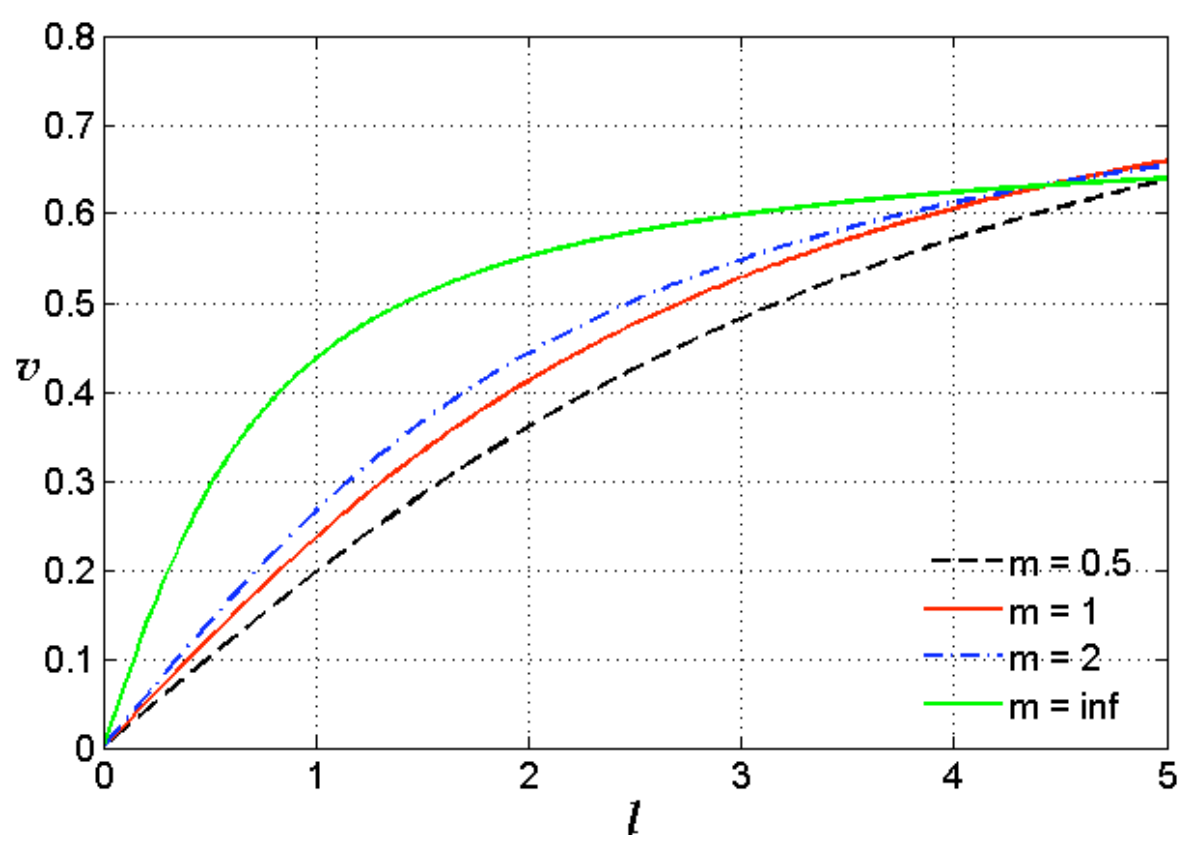

Fig. (7). Temporal distribution of landslide velocity in point $X=L / 2\left(q=1, L_{0}=1\right)$.

Using (19) and (24) we can express velocity distribution in the landslide body through landslide length

$$
v=\frac{p X}{L} \sqrt{1-\left(\frac{L_{0}}{L}\right)^{\frac{m}{m+1}}},
$$

Velocity increases in both directions from the landslide centre (in modulus) and decreases with time. Fig. (7) demonstrates temporal evolution of the velocity on the landslide for various cross-section shapes.

\section{CONCLUSION}

Computing landslide dynamics is an extremely important task in natural hazard assessments, and various physical and numerical models are developed. Analytical solutions allow studying the physical features of such processes (beginning of movement, direction of the landslide motion, spreading, forming of shocks and so on). Analytical solution for landslide dynamics in underwater canyons approximated by channels of parabolic-like cross-section was obtained here in the framework of the ideal shallow-water flow (SavageHutter model). Obtained solutions show that the cross section of the submarine canyon influences significantly on landslide parameters in time. The avalanche edge is quasi beak-shaped in the channel of the cross section $(m=0.5)$ and near lozenge-shaped in the triangular cross section $(m=$ 1 ); it has ellipsoidal shape for $m>1$. Thus, the length of the parabolic cap depends on the cross-section of shape and it 
increases faster for concave channels (for the same value of the spreading parameter). Asymptotically, the landslide length varies almost linearly with time. Furthermore, landslide height decreases slowly particularly in channels of parabolic cross section. In whole, for landslides of same thickness nonlinear processes are developed more intensively in narrow canyons.

Analytical solutions given here can be used to test numerical codes of tsunami generation by the submarine landslides.

\section{ACKNOWLEDGEMENT}

Partial support came from French grant CPER (20072013), ANR project (Vitesss), ARC (DP0988449), RFBR (08-05-00069, 08-05-91850, 09-05-91222-CT, 09-05-00204) is gratefully acknowledged.

\section{REFERENCES}

[1] Heinrich P, Mangeney A, Guibourg S, Roche R. Simulation of water waves generated by a potential debris avalanche in Montserat, Lesser Antilles. Geophys Rese Lett 1998; 25: 3697 -700.

[2] Pelinovsky E, Zahibo N, Dunkley P, et al. Tsunami generated by the volcano eruption on July 12-13 2003 at Montserrat, Lesser Antilles. Sci Tsunami Hazards 2004; 22: 44-57.

[3] Zahibo N, Pelinovsky E, Kurkin A, Nikolkina I. In Krishnamurthy RR, Glavovic BC, Kannen A, Green DR, Ramanathan AL, Han Z, Tinti S, Agardy T, Eds. Tsunami hazard for the French West Indies, Lesser Antilles. Integrated Coastal Zone Management. Research Publ, Singapore 2008; pp. 517-35.

[4] Murty TS. Seismic sea waves - tsunamis. Bull. Fish. Res. Board Canada 198, Ottawa. 1977; pp. 337.

[5] Pelinovsky EN. Tsunami wave hydrodynamics. Institute Applied Physics Press: Nizhny Novgorod 1996; p 276.

[6] Levin B, Nosov M. Physics of Tsunamis. Springer. 2009; pp. 327.

[7] Harbitz C. Model simulations of tsunamis generated by the Storegga Slide. Mar Geol 1992; 104: 1-21.

[8] Pelinovsky E, Poplavsky A. Simplified model of tsunami generation by submarine landslides. Phys Chem Earth 1996; 21: 13-7.

[9] Watts P. Tsunami features of solid block underwater landslides. J Waterway Port Coast Ocean Eng 2000; 126(3): 144-52.

[10] Tinti S, Bortolucci E, Chlavettieri C. Tsunami excitation by submarine slides in shallow-water approximation. Pure Appl Geophys 2001, 158: 759-97.

[11] Liu PL-F, Lynett P, Synolakis CE. Analytical solutions for forced long waves on a sloping beach. J Fluid Mech 2003; 478: 101-9.

[12] Pelinovsky E. In Yalciner A, Pelinovsky E, Okal E, Synolakis C, Eds. Analytical models of tsunami generation by submarine landslides. Submarine landslides and tsunamis. The Netherland: Kluwer 2003; Vol. 21: pp. 111-28.

[13] Sammarco P, Renzi E. Landslide tsunamis propagating along a plane beach. J Fluid Mech 2008; 598: 107-119.
[14] Romstad R, Harbitz CB, Domaas U. A GIS method of rock slide tsunami hazard in all Norwegian lakes and reservoirs. Nat Hazards Earth Syst Sci 2009; 9: 353-64.

[15] Imamura F, Gica EC. Numerical model for tsunami generation due to subaqueous landslide along a coast, Sci Tsunami Hazards 1996; 14: $13-28$.

[16] Mangeney A, Heinrich P, Roche R. Analytical solution for testing debris avalanche numerical models. Pure Appl Geophys 2000; 157: 1081-96.

[17] Assier-Rzadkiewicz S, Heinrich P, Sabatier PC, Savoyer B, Bourillet JF. Numerical modeling of a landslide-generated tsunami: the 1979 Nice event. Pure Appl Geophys 2000; 157: 1707-27.

[18] Bouchut F, Mangeney-Castelnau A, Perthame B, Vilotte J-P. A new model of Saint Venant and Savage-Hutter type for gravity driven shallow water flows. CR Acad Sci Paris Ser 1 2003; 1336: 531-36.

[19] Fine IV, Rabinovich AB, Thomson RE, Kulikov EA. In: Yalciner A, Pelinovsky E, Okal E, Synolakis C, Eds. Numerical modeling of tsunami generation by submarine and subaerial landslides. Submarine landslides and tsunamis. The Netherland: Kluwer 2003; Vol. 21: pp. 69-88.

[20] Fine IV, Rabinovich AB, Bornhold BD, Thomson RE, Kulikov EA. The Grand Banks landslide-generated tsunami of November 18, 1929: preliminary analysis and numerical modeling. Mar Geol 2005; 215: 45-57.

[21] Le Friant A, Boudon G, Komorowski J-C, Heinrich P, Semet MP. Potential flank-collapse of Soufriere Volcano, Guadeloupe, Lesser Antilles? Numerical simulation and hazards. Nat Hazards 2006; 39: 381-93.

[22] Fernandez-Feria R. Dam-break flow for arbitrary slopes of the bottom. J. Eng Math 2006; 54: 319-31

[23] Yalciner AC, Pelinovsky E, Synolakis C, Okal E. Submarine Landslides and Tsunamis, NATO Science Series. Kluwer Academic Publishers: Netherlands 2003; p. 240.

[24] Savage SB, Hutter K. The motion of a finite mass of granular material down a rough incline. J Fluid Mech 1989; 199: 177-215.

[25] Savage SB, Hutter K. Dynamics of avalanches of granular materials from initiation to run-out. Part 1: Analysis. Acta Mech 1991; 86: 201-23

[26] Pudasaini SP, Hutter K. Avalanche dynamics: dynamics of rapid flows of dense granular avalanches. New York: Springer. 2007; p. 602.

[27] Zahibo N, Pelinovsky E, Golinko V, Osipenko N. Tsunami wave runup on coasts of narrow bays. Int J Fluid Mech Res 2006, 33: 106-18.

[28] Monterey Bay Aquarium Research Institut [homepage on the Internet], updated 2009 April 22, Available from: http://www.mbari.org//[cited 2009 May 15].

[29] Stoker JJ. Water waves: The mathematical theory with applications. New York: Interscience 1957; p. 600

[30] Carrier GF, Greenspan HP. Water waves of finite amplitude on a sloping beach. J Fluid Mech 1958; 4: 97-109.

[31] Choi BH, Pelinovsky E, Kim DC, Didenkulova I, Woo SB. Twoand three-dimensional computation of solitary wave runup on nonplane beach. Nonlinear Process Geophys 2008; 15: 489-502.

(C) Zahibo et al.; Licensee Bentham Open.

This is an open access article licensed under the terms of the Creative Commons Attribution Non-Commercial License (http://creativecommons.org/licenses/ by-nc/3.0/) which permits unrestricted, non-commercial use, distribution and reproduction in any medium, provided the work is properly cited. 